\title{
Phase Diagrams for Crystal Growth
}

\author{
Manfred Mühlberg
}

1.1

Introduction

The operating abilities of a large part of modern technological hardware (electronic and optic devices, control and operating systems, watches, etc.) is based on active and/or passive crystalline core pieces. For various applications the crystalline state is required to be polycrystalline (ceramics), multigrained (solar cells), crystalline designed (thin film sequences) or single crystalline (semiconductor and NLO devices, $\mathrm{CaF}_{2}$ lenses, prisms, etc.). The dimension of the crystallites and crystals covers a wide range from $<\mathrm{nm}>$ (nanocrystallites) and $<\mu \mathrm{m}>$ (ceramics, thin-film arrangements) up to $<m m>$ and $<c m>$ scales (electronics, optics), in special cases up to $<\mathrm{m}>$ scale (silicon single crystals, natural ice and quartz crystals).

This chapter is only focused on the growth conditions of so-called single crystals in the dimension of $<\mathrm{mm}>$ and $<\mathrm{cm}>$ scale. The fabrication of such single crystals is normally connected with the well-established growth methods named after Bridgman, Czochralski, Verneuil or zone melting, top seeded solution growth (TSSG), recrystallization techniques, etc. All these methods can be described by the following definition of crystal growth:

1. In growing single crystals, one is primarily concerned with obtaining a crystal of predetermined size with a high degree of structural perfection and a well-determined chemical composition.

2. Growth of a single crystal requires the nucleation, subsequent growth, eventual termination of the process and, finally, removal of the crystal from the apparatus.

3. The transition into the solid/crystalline state can be realized from the vapor phase, liquids or a polycrystalline solid phase. Liquid phases are melts or high- or low-temperature solutions. The growth from liquid phases plays the most important role.

4. Each step of the growth process is affected by controlling the experimental parameters pressure $p$, temperature $T$, and concentration (of components) $x_{i}$.

Crystal Growth Technology. Edited by Hans J. Scheel and Peter Capper Copyright $\odot 2008$ WILEY-VCH Verlag GmbH \& Co. KGaA, Weinheim ISBN: 978-3-527-31762-2 
Paragraphs (1) and (2) are primarily determined by the growth method and optimized technological parameters. Paragraphs (3) and (4) are correlated with some thermodynamic terms: phases, pressure, temperature, and concentration. In a pictorial representation crystal growth means to start in a $p-T-x_{i}$ phase space at any point $p_{0}, T_{0}, x_{i}^{\left({ }^{\circ}\right)}$. By default, the final point of the growth process is fixed at the normal atmospheric pressure, room temperature and a desired crystal composition. One (i), in some cases two (ii) challenges must be overcome between the starting and final point in the phase space.

i. A phase transition (of first order) is necessary for the transfer into the solid/crystalline state. They are denoted as sublimation, solidification, precipitation, recrystallization, etc.

ii. Additionally, one or more phase transitions may exist in the solidified material between the starting and final point. The kinds of solid/solid phase transitions are very varied (Rao and Rao [1]), and the structural quality of the grown crystal is strongly influenced by the type of these phase transitions. Ferroelectric compounds play an important role in several technical applications. For this reason, ferroelectric phase transitions, classified as phase transition of second order, are of special interest in crystal growth. The most important materials undergoing ferroelectric phase transitions are members of the perovskite group $\left(\mathrm{LiNbO}_{3}, \mathrm{BaTiO}_{3}, \mathrm{KNbO}_{3}\right)$ and the tetragonal tungsten bronzes (strontium barium niobate $(\mathrm{SBN})$, calcium barium niobate $(\mathrm{CBN})$, potassium lithium niobate (KLN), and potassium titanyl phosphate (KTP = $\left.\mathrm{KTiOPO}_{4}\right)$.

Phase diagrams represent all these transitions. Consequently, the determination, knowledge and understanding of phase diagrams are one of the essential preconditions for selection and basic application of the growth method and the growth process.

\section{2}

\section{Thermodynamics and Phase Diagrams}

Phase diagrams are the reflection of thermodynamic laws and rules between different phases in the $p-T-x_{i}$ phase space. The general thermodynamic background is given in textbooks (e.g. [2, 3]). There are also some distinguished overviews (e.g. [4]) and collections of selected phase diagrams (e.g. [5]). The aim of this chapter is to give an overview and understanding of phase diagrams with the dedicated focus to crystal growth. The basic thermodynamic functions and variables are seen as prerequisite and are not included in this chapter (see Chap. 2).

As mentioned above, the crystallization process is a phase transition of first order characterized by a jump of the latent (transition) heat, volume and several physical and chemical properties like heat conductivities, densities etc. The latent heat $\Delta H_{\text {tr }}$ must be considered as the first important parameter. 
1.2 Thermodynamics and Phase Diagrams $\mid 5$

Table 1.1 Typical values for the heat and entropy of transformation.

\begin{tabular}{lcc}
\hline Kind of transformation & $\begin{array}{c}\text { Heat of transformation } \\
\Delta H_{\mathrm{tr}}[\mathrm{kJ} / \mathrm{mole}]\end{array}$ & $\begin{array}{c}\text { Entropy of transformation } \\
\Delta S_{\mathrm{tr}}\left[\frac{\mathrm{J}}{\mathrm{K} \cdot \mathrm{mole}}\right]\end{array}$ \\
\hline solid/solid & & \\
first order & $1-(5)$ & $<10$ \\
solid/liquid & 10 (metals) & 10 \\
& $10-100$ comp. & $10-50$ \\
liquid/vapor & $10-100$ (elem.) & 10 \\
& $>100$ (comp.) & \\
\hline
\end{tabular}

In particular, some growth processes from the melt have relatively high growth rates, being influenced by release of the heat of fusion. There are the following relationships between the different kinds of latent heat (legend: s/s - solid/solid; fus - fusion; vap - vapor; sub - sublimation):

$$
\Delta H_{\mathrm{s} / \mathrm{s}}<\Delta H_{\text {fus }}<\Delta H_{\text {vap }} ; \Delta H_{\text {sub }}=\Delta H_{\text {fus }}+\Delta H_{\text {vap }} ; \Delta H_{\text {fus }}<<\Delta H_{\text {sub }}
$$

Table 1.1 shows typical values being valid for the heats and entropies of transformation. The latent heats cover a range of two orders of magnitude, and we will see later the distinctive consequences on the kind and appearance of phase diagrams.

\subsection{1}

\section{One-component Systems}

The second important thermodynamic function is the Gibbs free energy $G$ describing the convertible energy amount between two phases. In an equilibrium state between two phases in a one-component system one can write the following approach for the change of the free energy

$\mathrm{d} G_{\text {phase1 }}=\mathrm{d} G_{\text {phase2 }}$

$\left(V_{p 2}-V_{p 1}\right) \mathrm{d} p-\left(S_{p 2}-S_{p 1}\right) \mathrm{d} T=0$

Considering:

$$
\begin{aligned}
\left(S_{p 2}-S_{p 1}\right)=\frac{\Delta H_{\mathrm{tr}}}{T} ; \mathrm{d} V \mathrm{~d} p-\Delta H_{\mathrm{tr}} \frac{\mathrm{d} T}{T}=0 \\
\frac{\mathrm{d} T}{\mathrm{~d} p}=\frac{\Delta H_{\mathrm{tr}}}{T \cdot \Delta V} \text { and } / \text { or } \frac{\mathrm{d} T}{\mathrm{~d} p}=\frac{T \cdot \Delta V}{\Delta H_{\mathrm{tr}}}
\end{aligned}
$$

Equations (1.5), also called the Clausius-Clapeyron (CC) equations, describe the temperature dependence of the vapor pressure and the dependence of the vapor pressure on the (melting) temperature, respectively. The consequences can be seen 
6| 1 Phase Diagrams for Crystal Growth

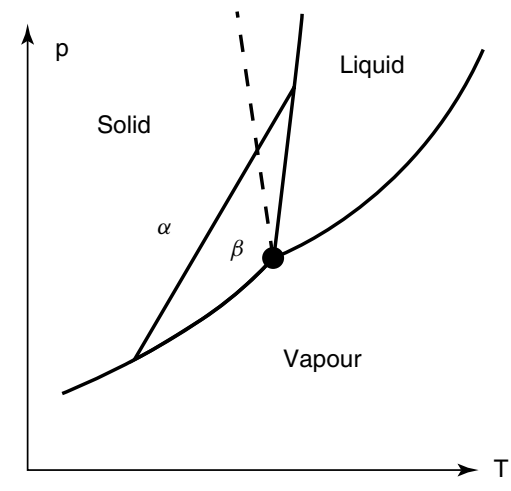

(a)

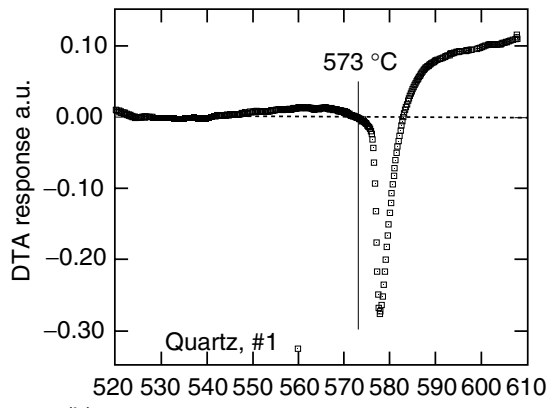

(b)

Temperature ${ }^{\circ} \mathrm{C}$

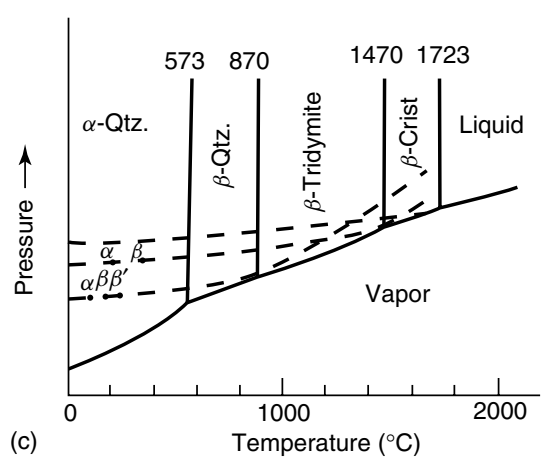

Fig. 1.1 Ideal (top left) and real $\left(\mathrm{SiO}_{2}[2]\right.$, top right) one-component system. DTA plot of the $\alpha-\beta$ quartz phase transition.

at a simple one-component phase diagram, which can be articulated completely by the CC equation.

For a solid/liquid phase transition the steepness of $\mathrm{d} p / \mathrm{d} T$ can be greater or less than zero caused by a positive or negative volume difference between the two phases. In most cases, these differences are positive, i.e. the volume of the liquid phase is greater than the volume of the solid state (see top left image in Fig. 1.1). Furthermore, $\Delta V$ is very small for solid/liquid and solid/solid transitions, and the pressure dependence on the melting point is also very small, typically in the range of $10^{-3} \mathrm{~K} /$ bar. Additionally, a differential thermal analysis (DTA) plot of the well-known $\alpha \leftrightarrow \beta$ quartz transition is given in the top right picture of Fig. 1.1. The plot displays a heat effect for this transition being typical for phase transitions of first order. On the other side, the $\alpha \leftrightarrow \beta$ quartz transition can be specified using the Landau theory by a typical phase transition of second order. The rotation $\delta$ of the $\mathrm{SiO}_{2}$ tetrahedrons between $16^{\circ} \mathrm{C}$ (at room temperature) and $0{ }^{\circ} \mathrm{C}\left(\right.$ at $573{ }^{\circ} \mathrm{C}$ ) is the order parameter and satisfies the classical rule $\delta \sim\left(T-T_{\text {tr }}\right)^{1 / 2}$. Table 1.2 shows some examples for a positive and/or negative slope of the solid/liquid transition. 
Table 1.2 Slope of $d T / d p$ for the types of phase transitions: solid/solid, solid/liquid and liquid/vapor.

\begin{tabular}{lrrr}
\hline$\frac{\mathrm{d} T}{\mathrm{~d} p}$ (K/bar) & $\boldsymbol{s} \leftrightarrow \boldsymbol{s}$ & $\boldsymbol{s} \leftrightarrow \boldsymbol{I}$ & $I \leftrightarrow \boldsymbol{v}$ \\
\hline $\mathrm{Ag}$ & & $+4 \times 10^{-3}$ & \\
$\mathrm{H}{ }_{2} \mathrm{O}$ & & $-8 \times 10^{-3}$ & 28.01 \\
$\mathrm{CdSe}$ & & $-0.2 \times 10^{-3}$ & \\
$\mathrm{HgTe}$ & & $+4.5 \times 10^{-3}$ & \\
$\alpha \leftrightarrow \beta$ Quartz & 0.021 & & \\
$\alpha=$ Quartz. $\leftrightarrow$ Tridymite & 0.620 & & \\
& & & \\
\hline
\end{tabular}

For transitions from a condensed phase into the vapor phase (the vapor phase is assumed to be perfect: $\left.V_{\mathrm{v}}-V_{\text {cond }} \approx V_{\mathrm{v}}=R \cdot T / p\right)$ the solution of the CC equation results in

$$
p=p_{0} \cdot \exp \left(\frac{\Delta H_{\mathrm{tr}}}{R}\left(\frac{1}{T_{0}}-\frac{1}{T}\right)\right)
$$

The one-component system can be easily expanded by Raoult's and van't Hoff's laws if it is diluted. These laws describe that a low solute composition $x_{\mathrm{B}}$ reduces the freezing point of a solid phase and the partial pressure over a liquid phase (see Fig. 1.2).

Raoult's law: $p_{\mathrm{S}}=\left(1-x_{\mathrm{B}}\right) \cdot p_{0(\mathrm{~A})}$

van't Hoff equations:

boiling point elevation : $\frac{\Delta T}{T_{\mathrm{v}}}=x_{\mathrm{B}} \cdot \frac{R T_{\mathrm{v}}}{\Delta H_{\mathrm{v}}}$

freezing point depression : $\frac{\Delta T}{T_{\mathrm{m}}}=-x_{\mathrm{B}} \cdot \frac{R T_{\mathrm{m}}}{\Delta H_{\mathrm{f}}}$

Equation (1.9) is useful to derive solubility curves from limited solubility data.

1.2 .2

\section{Multicomponent Systems}

For a multicomponent system Eqs. (1.2) and (1.3) can be primary extended by a term describing the composition influence of the participated components $x_{\mathrm{A}, \mathrm{B}, \mathrm{C}, \ldots}$. The thermodynamic activity of any component (e. g. A) is expressed by the chemical potential $\mu_{\mathrm{A}}{ }^{i}=\mu_{\mathrm{A}}{ }^{i(0)}+R \cdot T \ln x_{\mathrm{A}}^{(i)} ; i$ corresponds to solid or liquid or vapor. The chemical potential can be understood in terms of the Gibbs free energy per mole of substance, and it demonstrates the decreasing influence of a pure element or a compound in a diluted system. If any pure component is diluted then the term $R \cdot T$ $\ln x_{\mathrm{A}}{ }^{(i)}$ will always take values lower than zero (note, that only an ideal solution behavior is considered by the mole fraction $x_{\mathrm{A}}$. For real cases the so-called activity 
8| 1 Phase Diagrams for Crystal Growth

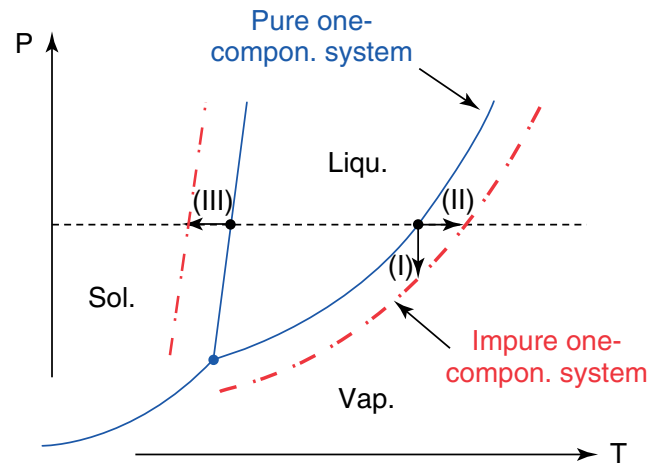

Fig. 1.2 Extension of a one-component system by adding a solute; $p_{\mathrm{s}}$ - vaboiling point, melting point; $\Delta T=T-T_{\mathrm{v}}$; por pressure over a dilute $\Delta T=T-T_{m}-$ absolute boiling point elevation or solution; $p_{\mathrm{o}(\mathrm{A})}$ - vapor pres- freezing point depression; sure of the pure solvent $\mathrm{A} ; \quad \Delta \mathrm{H}_{\mathrm{v}}, \Delta \mathrm{H}_{\mathrm{f}}$ - heat of vapor$x_{\mathrm{B}} \Delta$ mole fraction of an ization, heat of fusion. impurity; $T_{\mathrm{v}}, T_{\mathrm{m}}-$

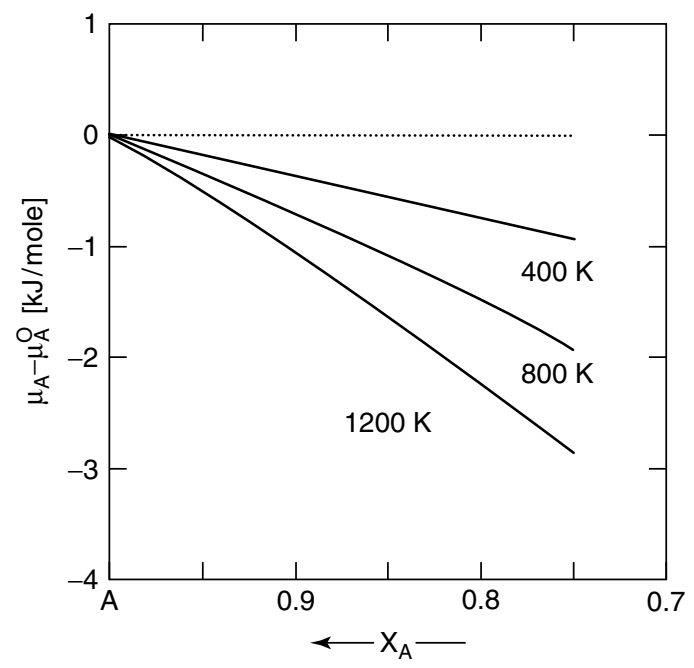

Fig. 1.3 The chemical potential of a pure component is reduced in a binary system; it is also a function of temperature; $\mu_{A}{ }^{0}$ is the chemical potential of the pure compound $\mathrm{A}$.

$a_{\mathrm{A}}=f_{\mathrm{A}} \cdot x_{\mathrm{A}}$ must be used. The activity coefficient $f_{\mathrm{A}}$ collects all deviations from an ideal solution behavior). Figure 1.3 shows the reducing influence in a diluted solution as a function of the temperature. 
Accepting that all processes have to be discussed in a $p-T-x_{i}$ phase space, Eq. (1.10) describes the complete change $\mathrm{d} G$ of the free energy of a multicomponent system.

$$
\mathrm{d} G=V \mathrm{~d} p-\underbrace{S \mathrm{~d} T+\sum_{i=1}^{n} \mu_{i} \mathrm{~d} x_{i}}_{T-x_{i} \text { phase diagrams }}+\mathrm{d} \gamma_{\text {surf }}+(. .) \mathrm{d} \varepsilon_{\text {elast }}
$$

For many processes the vapor pressure can be neglected and also the last two terms must only be considered for small particles (surface influence) or nucleation inside of a solid phase (elastic strain). They can be neglected for any bulk growth processes from the liquid or vapor phase. These assumptions are the basis for the presentation of the technical important $T-x$ phase diagrams. Equation (1.10) is reduced for the case of a two-component system A-B to

$$
\mathrm{d} G=V \mathrm{~d} p-S \mathrm{~d} T+x_{\mathrm{A}} \mathrm{d} \mu_{\mathrm{A}}+x_{\mathrm{B}} \mathrm{d} \mu_{\mathrm{B}}
$$

Using the chemical potential as the "partial molar Gibbs free energy" in Eq. (1.12) and accepting that many processes are running at a nearly constant pressure ( $p=$ const.; $\mathrm{d} p=0$ ) one can rewrite Eq. (1.12) to Eq. (1.13) for a two component system A-B in solid(s)/liquid(l) equilibrium

$$
\begin{aligned}
& \mathrm{d} \bar{G}_{\mathrm{A}}^{\mathrm{s}}=\mathrm{d} \bar{G}_{\mathrm{A}}^{1} \quad \mathrm{~d} \bar{G}_{\mathrm{A}}=\frac{\mathrm{d} G}{\mathrm{~d} x_{\mathrm{A}}} \\
& -\left(\bar{S}_{\mathrm{A}}^{\mathrm{s}}-\bar{S}_{\mathrm{A}}^{1}\right) \mathrm{d} T+R T \cdot \mathrm{d} \ln \frac{x_{\mathrm{A}}^{\mathrm{s}}}{x_{\mathrm{A}}^{1}}=0
\end{aligned}
$$

Replacing $-\left(\bar{S}_{\mathrm{A}}^{\mathrm{S}}-\bar{S}_{\mathrm{A}}^{1}\right)$ by $\frac{\Delta H_{\text {fus }}}{T}$ and integrating Eq. (1.13) gives the final expression for an ideal binary phase diagram of a solid solution system A-B. This equation is also indicated as the van Laar equation for a two-component system $\mathrm{A}-\mathrm{B}[3]$.

$$
\ln \frac{x_{\mathrm{A}}^{\mathrm{s}}}{x_{\mathrm{A}}^{1}}-\ln \frac{x_{\mathrm{B}}^{\mathrm{s}}}{x_{\mathrm{B}}^{1}}=\frac{\Delta H_{\mathrm{A}}}{R T}\left(1-\frac{T}{T_{\mathrm{A}}}\right)-\frac{\Delta H_{\mathrm{B}}}{R T}\left(1-\frac{T}{T_{\mathrm{B}}}\right)
$$

The van Laar equation is only determined by the two melting points $T_{\mathrm{A}}, T_{\mathrm{B}}$ and the heats of fusion $\Delta \mathrm{H}_{\mathrm{A}}, \Delta H_{\mathrm{B}}$ of the end members $\mathrm{A}$ and $\mathrm{B}$. Their influence on the shape of a solid solution system can easily be shown on a PC if the equation is converted in parametric functions [Eqs. (1.15) and (1.16)] and calculated by any data and function plotting utility (e.g. Gnuplot [6], see Fig. 1.4).

Equations (1.15) and (1.16) illustrate the parametric function for the solidus and liquidus curve

$$
x_{\mathrm{B}}^{\mathrm{s}}=\frac{\exp \left\{\frac{\Delta H_{\mathrm{A}}}{R}\left(\frac{1}{T}-\frac{1}{T_{\mathrm{A}}}\right)\right\}-1}{\exp \left\{\frac{\Delta H_{\mathrm{A}}}{R}\left(\frac{1}{T}-\frac{1}{T_{\mathrm{A}}}\right)-\frac{\Delta H_{\mathrm{B}}}{R}\left(\frac{1}{T}-\frac{1}{T_{\mathrm{B}}}\right)\right\}-1}
$$




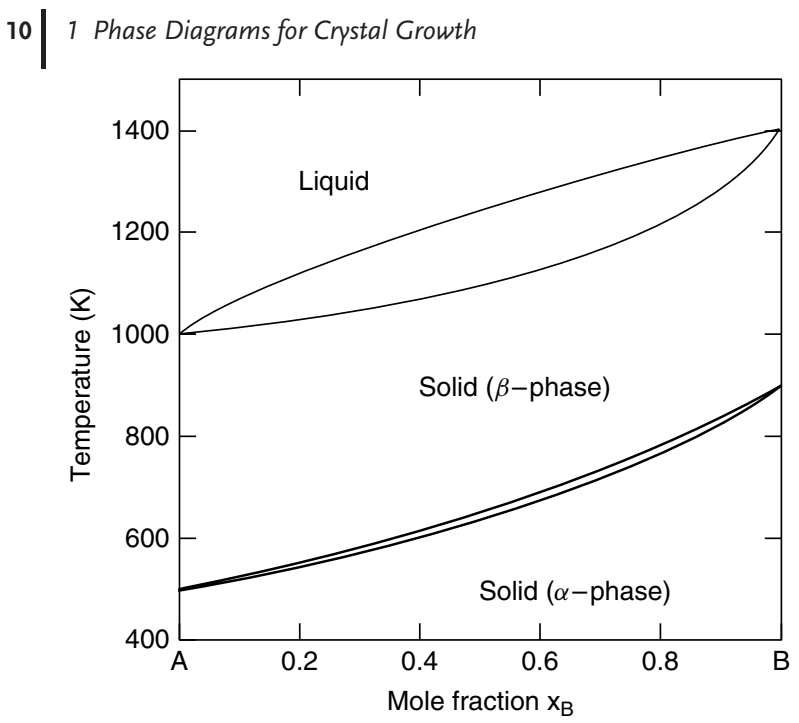

Fig. 1.4 Application of the van Laar equation to a solid/liquid and a $\operatorname{solid}(\alpha) / \operatorname{solid}(\beta)$ with random, but typical values.

$$
x_{\mathrm{B}}^{1}=\frac{\exp \left\{\frac{\Delta H_{\mathrm{A}}}{R}\left(\frac{1}{T}-\frac{1}{T_{\mathrm{A}}}\right)\right\}-1}{\exp \left\{\frac{\Delta H_{\mathrm{A}}}{R}\left(\frac{1}{T}-\frac{1}{T_{\mathrm{A}}}\right)\right\}-\exp \left\{\frac{\Delta H_{\mathrm{B}}}{R}\left(\frac{1}{T}-\frac{1}{T_{\mathrm{B}}}\right)\right\}}
$$

Examples for a binary complete solid solution system for the a) solid $\leftrightarrow$ liquid transition:

(with $\Delta \mathrm{H}_{\mathrm{A}}^{\mathrm{f}}=\Delta H_{\mathrm{B}}^{\mathrm{f}}=50 \mathrm{k} / \mathrm{mole}$, and for melting points: $T_{\mathrm{A}}=1000 \mathrm{~K} ; T_{\mathrm{B}}=1400 \mathrm{~K}$ ) and for

b) $\alpha \leftrightarrow \beta$ phase transition:

(with $\Delta H_{\mathrm{A}}^{\mathrm{tr}}=\Delta H_{\mathrm{B}}^{\mathrm{tr}}=1.5 \mathrm{~kJ} / \mathrm{mole}$

transition temperatures: $\left.T_{\mathrm{A}}=500 \mathrm{~K} ; T_{\mathrm{B}}=900 \mathrm{~K}\right)$

are given in Fig. 1.4.

It can be seen in Fig. 1.5 that the higher the heats of fusion the broader the width between the liquidus and solidus lines of an ideal system. Furthermore, the difference between the heats of fusion determines the asymmetric shape of the phase diagram. In Section 1.3.1 the consequences of the shape of the solid solution phase diagrams on the segregation behavior in normal freezing growth processes will be discussed.

The extension to real cases and eutectic systems can be carried out in an analogous manner and is described by Kubaschewski and Alcock [7]. 

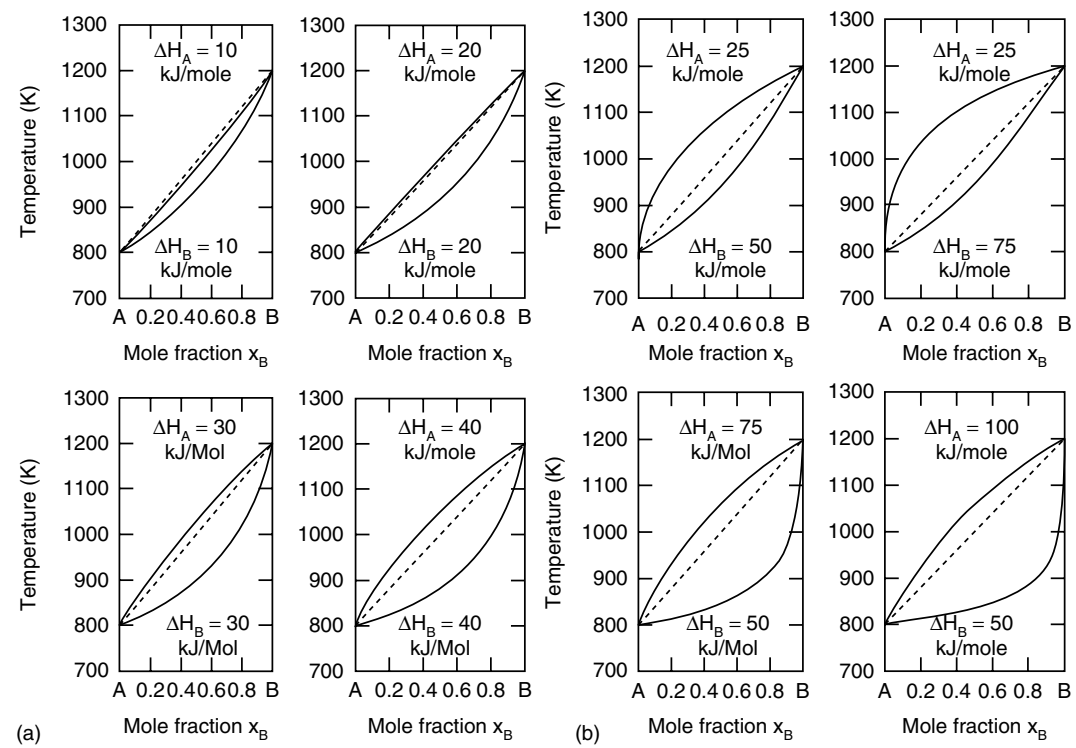

Fig. 1.5 Influence of the heat of fusion on the design of solid solution phase diagrams; calculated by Eqs. (1.15) and (1.16).

\section{2 .3}

\section{Gibbs Phase Rule and Phase Diagrams}

The main key for the understanding of phase diagrams is the phase rule of William Gibbs (1876)

$$
P+F=C+2
$$

where $P$ is the number of phases, $C$ is the number of components in the system, and $F$ is the number of freedom, or variance. The definition for the combined terms are: $P$ - any part of a system that is physically homogeneous within itself and bounded by a surface; component $C$ - smallest number of independently variable chemical constituents and degree of freedom - smallest number of intensive variables (e.g. $p, T, x_{i}$ of components in each phase) that must be specified to completely describe the state of the system.

Phase diagrams are the graphical representations of the phase rule, and they are classified by the number of components as follows: one-, two-, three-, ... component systems. On the other side, the phase rule is the most important tool for verifying phase diagrams. If pressure is omitted as a variable, the number of variables in a system is two: temperature and composition. The phase rule reduces to $F=C-P+1$ and in this form is referred to as the condensed phase rule or phase rule for condensed systems. As an example, let us discuss the application of the phase rule on a simple three-component system A-B-C with one compound BC. 


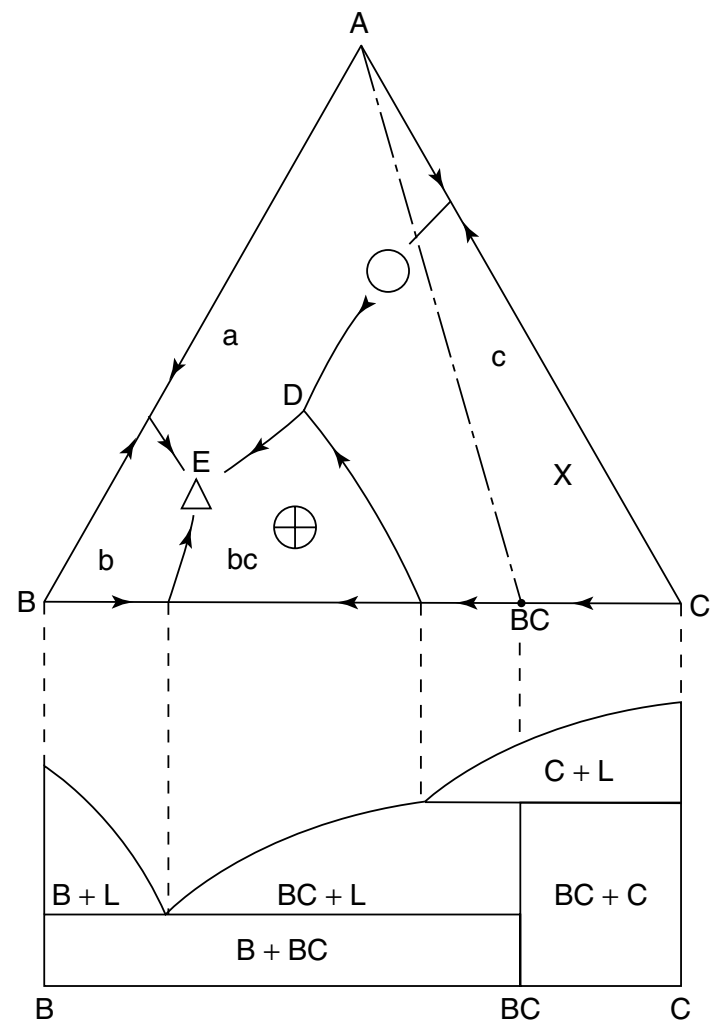

Fig. 1.6 Application of the Gibbs phase rule on three special points in a simple three-component system. The phase diagram was taken from [2].

If at least one phase exists then there is a four-dimensional phase space determined by the variables: $p, T, x_{\mathrm{A}}, x_{\mathrm{B}}$. As an illustration, we have to reduce the dimension of the phase space. In the first step a constant pressure is assumed and the phase space is reduced to a trihedral prism with the coordinates $T, x_{\mathrm{A}}, x_{\mathrm{B}}$. Normally, the projection onto this trihedral prism is used for printing processes. Figure 1.6 and the legend give the explanation for the relationship between the number of phases and the number of freedom.

$$
\begin{aligned}
& P=1 \rightarrow F=4 p, T, x_{\mathrm{A}}, x_{\mathrm{B}} \text { phase space } \\
& P=1 \rightarrow F=3 \mathrm{~T}, x_{\mathrm{A}}, x_{\mathrm{B}} \text { phase space, if } p=\text { const. } \\
& P=2 \rightarrow F=2 \mathrm{BC}_{\text {sol. }}+\operatorname{melt}(\oplus) \\
& P=3 \rightarrow F=1(\mathrm{~A}+\mathrm{BC})_{\text {sol. }}+\operatorname{melt}(\mathrm{O}) \\
& P=4 \rightarrow F=1(\mathrm{~A}+\mathrm{B}+\mathrm{BC})_{\text {sol. }}+\operatorname{melt}(\Delta)
\end{aligned}
$$

There are several violations of the phase rule resulting in incorrect description of phase relationships. Instructive examples of such thermodynamically impossible 


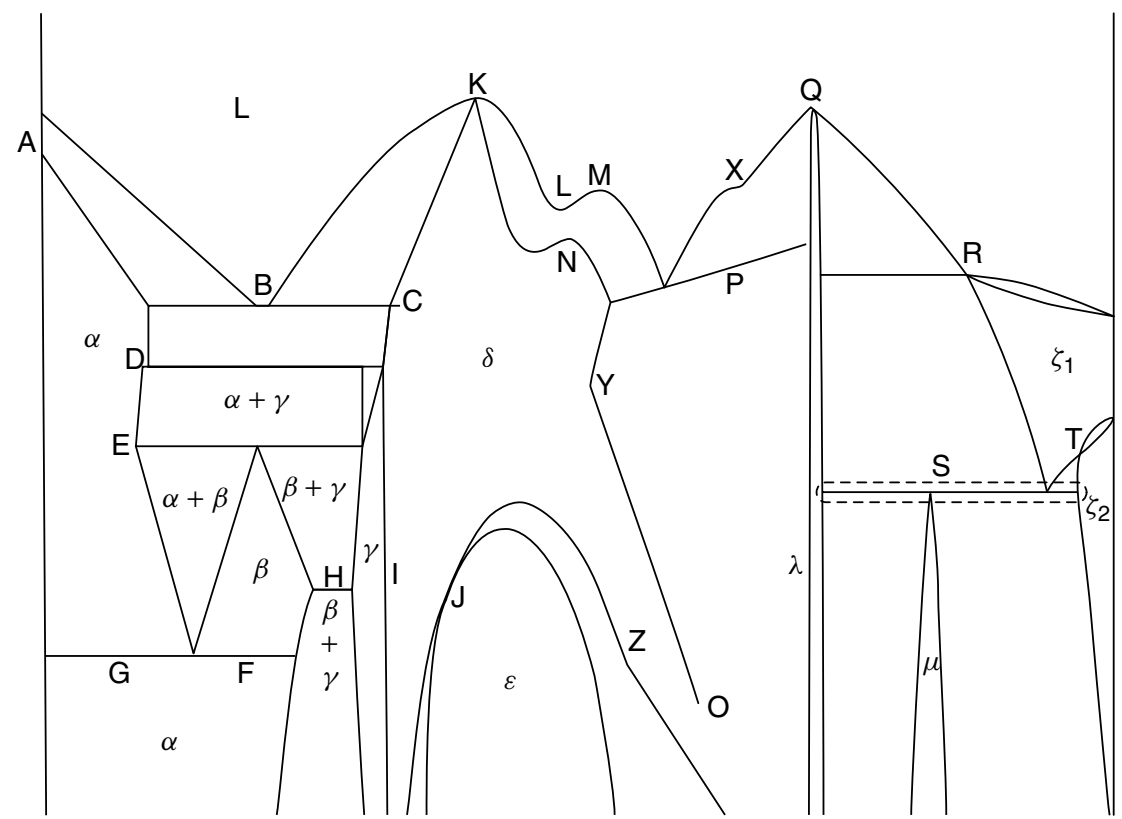

Fig. 1.7 Fictive binary phase diagram with several violations, after Okamoto und Massalski [8].

situations were given by Okamoto and Massalski [8] expressed by a fictive binary phase diagram (points A-T in Fig. 1.7).

1.3

\section{Phase Diagrams vs. Crystal Growth from Liquid Phases}

This section will describe some special problems, violations and handicaps of crystal growth associated with different types of phase diagrams. Growth of bulk crystals from the liquid state plays a dominant role for many technical applications and also in basic research. For this reason, the section is focused on growth processes from the melt, from high-temperature solutions and from aqueous solutions. The variable pressure cannot be neglected, but it is accepted to have little influence for many material systems, also at elevated temperature.

Figure 1.8 in combination with Table 1.3 shows basic types of binary phase diagrams being responsible for the mentioned growth processes. Some material systems will be selected and discussed in more detail.

Only one type has the identical composition of the melt and the solid crystalline phase at a congruent melting composition/point. This point corresponds to a distribution coefficient $k_{\mathrm{o}}=1$, and it is the best condition for growth from a liquid phase. An equilibrium between the solid and liquid phase in all other cases is characterized by a composition difference and consequently the existence of 
14 1 Phase Diagrams for Crystal Growth

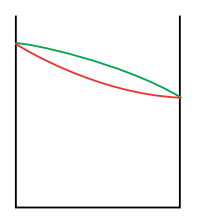

$C_{1} \neq C_{\mathrm{s}}$

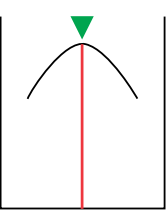

$C_{l}=C_{\mathrm{s}}$

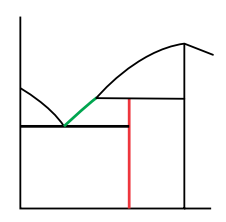

$C_{1} \neq C_{\mathrm{s}}$

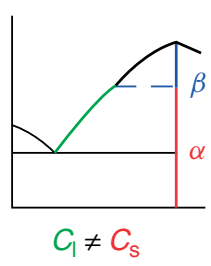

Fig. 1.8 Important phase diagram types being relevant for crystal growth from the melt and from solution.

Table 1.3 The four main types of the liquid/solid transition being important for crystal growth.

\begin{tabular}{|c|c|c|c|}
\hline Solid-solution system & Congruent melting & $\begin{array}{l}\text { Incongruent melting } \\
\text { - nonstoich. melt } \\
\text { - HT - solutions }\end{array}$ & $\begin{array}{l}\text { Eutectic system } \\
\text { - } \text { phase transition } \\
\text { - } \mathrm{T}_{\mathrm{m}} \text { lowering } \\
\text { - } \text { pressure lowering }\end{array}$ \\
\hline $\begin{array}{l}\text { Bridgman method } \\
\text { Czochralski method } \\
(\mathrm{Si}, \mathrm{Ge}) \\
(\mathrm{Hg}, \mathrm{Cd}) \mathrm{Te} \\
(\mathrm{Sr}, \mathrm{Ba}) \mathrm{NB}_{2} \mathrm{O}_{6} \\
\text { segregation!! }\end{array}$ & $\begin{array}{l}\text { Czochralski method } \\
\text { Bridgman method } \\
\mathrm{GaAs}_{\text {, InP }} \\
\mathrm{LiNbO}_{3}, \mathrm{SrTiO}_{3} \\
\text { garnets (e.g. YAG) } \\
\text { preferable }\end{array}$ & $\begin{array}{l}\text { TSSG, THM } \\
\text { solution growth } \\
\mathrm{KNbO}_{3} \\
\mathrm{KTiOPO}_{4} \text { (KTP) } \\
\text { garnet (YIG) } \\
\text { inclusions!! }\end{array}$ & $\begin{array}{l}\text { TSSG, THM } \\
\text { solution growth } \\
\mathrm{BaTiO}_{3} \\
\beta-\mathrm{BaB}_{2} \mathrm{O}_{4} \text { (BBO) } \\
\text { inclusions!! }\end{array}$ \\
\hline
\end{tabular}

distribution coefficients not equal to unity. Segregation of the components and capture of solvent are the main problems for growth from solutions. Inclusions are a form of growth instability that in the case of growth from melts can be prevented by high purity and by an appropriate temperature gradient at the growth front defined by the constitutional supercooling criterion. In growth from solutions, inclusions of solvent can be prevented by applying a growth rate below the maximum stable growth rate that can be derived from the phase diagram (concentration, solubility curve) as discussed in Chapter 6 of Elwell and Scheel [9]. Forced convection along the growth interface reduces the diffusion boundary layer, and thus allows to increase stable growth rates. Furthermore, the seeding of the growth process is complicated in these cases. The precise knowledge of the liquidus curve is required in order to avoid either spontaneous crystallization or dissolving of the seed crystal. For this reason, any crystal growth laboratory should closely cooperate with a laboratory for thermal analysis. Also, the reinvestigation of known and published phase diagrams is necessary in many cases. Figure 1.9 shows an example of considerable differences between published data and the reinvestigated phase diagram. 


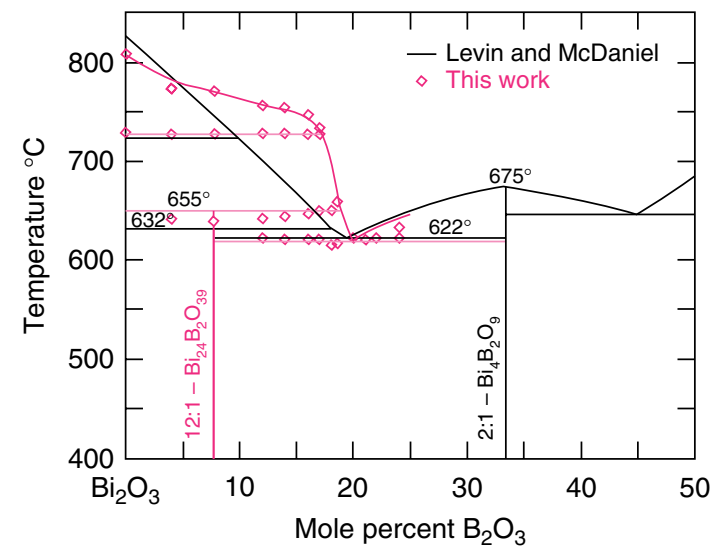

Fig. 1.9 Phase diagrams of growth of the sillenite-type the $\mathrm{Bi}$-rich side of the system $\mathrm{Bi}_{24} \mathrm{~B}_{2} \mathrm{O}_{39}$. The precise com$\mathrm{Bi}_{2} \mathrm{O}_{3}-\mathrm{B}_{2} \mathrm{O}_{3}$. Original data position of this sillenite was were taken by Levin and Mc- revised in a subsequent paDaniel [10]. This work means per to be $\mathrm{Bi}_{24.5} \mathrm{BO}_{38.25}$ [12]. the paper of Burianek and See text for further details Muehlberg [11]. The intention of the crystal growth of this of this investigation was to compound. find suitable conditions for

1.3.1

Solid-solution Systems

Segregation is always included in crystal growth of solid solution systems from the melt. The Bridgman and (in parts) the Czochalski method are termed normal freezing methods, i.e. the whole melt volume will be transferred into the solid state. In this well-arranged case the distribution function is described by the so-called Pfann/Scheil equation. A complete mixing of the melt at each time is assumed to exist for the derivation of this equation

$$
x_{\mathrm{S}}=k_{\mathrm{o}} \cdot x_{\mathrm{o}}\left(1-\frac{z}{L}\right)^{k_{\mathrm{o}}-1}
$$

with $x_{s}$ - crystal composition, $x_{0}$ - starting melt composition, $k_{0}-$ (nearly equilibrium) distribution coefficient, $z$ - current axial position, $L$ - total length of the crystal.

The distribution situation for $k_{\mathrm{o}}<1$ and $k_{\mathrm{o}}>$ should be known and is given in textbooks with respect to crystal growth. A nearly complete mixing at reduced growth velocities can be realized in many growth processes and the simplified conditions were very well reflected by Eq. (1.18).

A common problem in growth of solid solution crystals are striations, i.e. growth bands with varying concentrations. Striations are caused by temperature fluctuations, not by hydrodynamic fluctuations in a system of homogeneous temperature (Scheel and Swendsen [13], Scheel [14]). For the example of $\mathrm{KTa}_{1-x} \mathrm{Nb}_{x} \mathrm{O}_{3}$ 


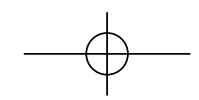

$16 \mid 1$ Phase Diagrams for Crystal Growth

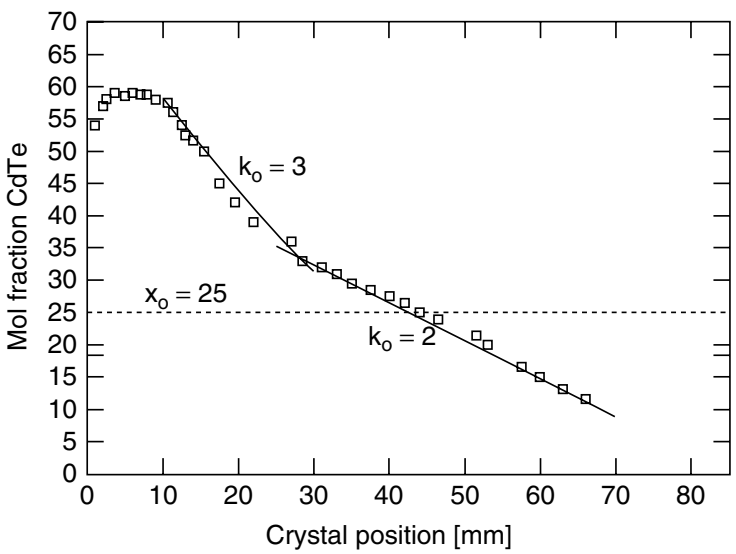

Fig. 1.10 Axial distribution in a $\mathrm{Hg}_{1-x} \mathrm{Cd}_{x} \mathrm{Te}$ crystal grown by the Bridgman method; $x_{0}=25$ mole fraction CdTe, $v=$ $0.33 \mathrm{~mm} / \mathrm{h}$, total length $L$ of the crystal: $85 \mathrm{~mm}$.

(KTN) Rytz and Scheel [15] have derived from the phase diagram the theoretical requirements of precise temperature control and forced convection to homogenize the high-temperature solution in order to achieve striation-free KTN crystals.

Considerable deviations from the ideal behavior expressed by Eq. (1.18) can be seen in growth of the complete solid solution system $(\mathrm{Hg}, \mathrm{Cd}) \mathrm{Te}$. This system shows a remarkable separation between the solidus and liquidus curve [16]. Figure 1.10 shows the axial segregation curve for a Bridgman-grown $\mathrm{Hg}_{1-x} \mathrm{Cd}_{x} \mathrm{Te}$ crystal. The curve can be classified into three parts: a) the first-to-freeze region has an abnormal course caused by spontaneous crystallization of the undercooled tip region in the ampoule. If low axial temperature gradients $\approx 10 \mathrm{~K} / \mathrm{cm}$ and very pure (semiconducting) materials are used then an undercooling of several centimeter is developed followed by a breaking down, abnormal segregation curve and a multigrained tip region [17]. b) + c) $k_{\mathrm{o}} \approx 3$ and $k_{\mathrm{o}} \approx 2$ region: because the splitting up of the liquidus and solidus curve, the values for $k_{\mathrm{o}}$ are not constant during the entire growth process.

\section{3 .2}

\section{Materials with a Congruently Melting Composition}

A materials system with a congruently melting composition is particularly suitable for crystal growth from the melt. Thus, only elements (e.g. silicon) or compounds with a congruently melting composition can be grown as large crystals for important technical applications. Note that for thermodynamic reasons, the exact congruently melting composition of compounds is not identical with its stoichiometric composition. There are deviations within the stability regions between nearly 0 and about 2 mole fraction. Figure 1.11 shows the simple binary phase diagram $\mathrm{Pb}-\mathrm{Te}$. PbTe crystallizing in the sodium chloride structure is the only 

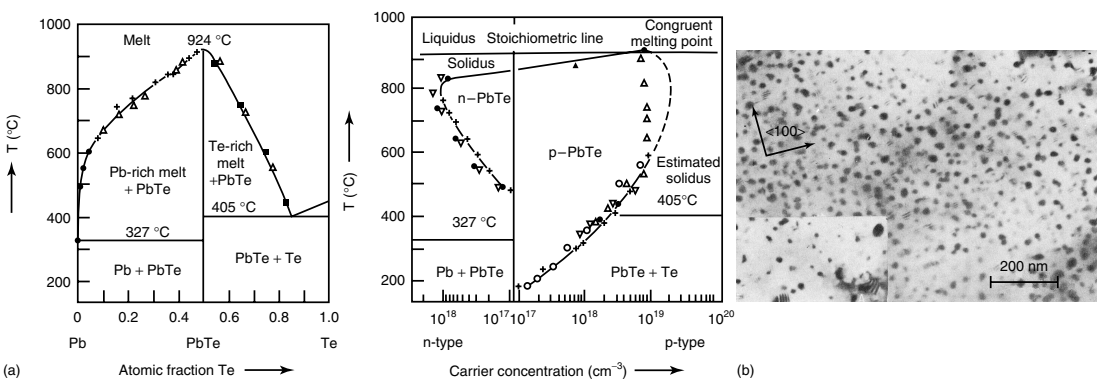

Fig. 1.11 Phase diagram of the binary system $\mathrm{Pb}-\mathrm{Te}$ and stability region of $\mathrm{PbTe}$ (left). Te precipitations in $\mathrm{PbTe}$ made visible by transmission electron microscopy (right) [19].

compound in this system. The stability region of PbTe covers the stoichiometric line and has been well investigated by Hall effect measurements of annealed and quenched samples. Deviations up to $10^{19} \mathrm{~cm}^{-3}$ can be easily detected because this level is about three orders of magnitude higher than the impurity level of the used $6 \mathrm{~N}$ materials (impurity level corresponds to about $10^{16} \mathrm{~cm}^{-3}$ ). All stability regions show a retrograde solubility. The retrograde solubility is responsible for formation of precipitates during the cooling process of a grown crystal. The right image in Fig. 1.11 shows small Te precipitations in PbTe detected by transmission electron microscopy and identified by electron diffraction and Moiré fringes.

An excellent introduction into the thermochemistry of nonstoichiometric compounds was given by Albers and Haas [18].

\section{3 .3}

\section{Materials with an Incongruently Melting Composition}

A distinctive feature in crystal growth of these materials is the composition difference between the liquid and solid phase, especially at the growing interface. The two right phase diagram types in Fig. 1.8 describe the crystal growth from high- or low-temperature solutions or from nonstoichiometric melts. Growth processes are characterized by a slow lowering of the temperature in order to force the crystallization. The mentioned phase diagram types in Fig. 1.8 allow growth of materials with incongruently melting compositions and materials with a solid/solid phase transition. Furthermore, the application of a suitable solvent or nonstoichiometric composition is capable of reducing a high growth temperature or pressure, so that growth close to thermal equilibrium may yield crystals with a high structural perfection. As am example, $\mathrm{SrTiO}_{3}$ can be mentioned that has been grown from the melt (Verneuil method), by top-seeded solution growth (TSSG), and at the lowest temperature from a Sr-Li-borate flux (Scheel et al. [20]). The measured dislocation densities of $10^{6}-10^{7}, 10^{1}-10^{2}$, and $0-10^{2} \mathrm{~cm}^{-2}$, respectively, 
18| 1 Phase Diagrams for Crystal Growth

demonstrate the improved structural perfection at decreasing growth temperature. Adverse aspects are the low growth rate ( $\approx$ grams per day) and the low crystal yield, especially if the slope $\frac{\Delta T}{\Delta x}$ of the liquidus curve is large. Concerning the solvent, there are several requirements (see also Chapter 3 of Elwell and Scheel [9]): high solubility of the component of interest, no (or low) chemical reactivity between material and solvent, low vapor pressure, minor differences in heat conductivity between the material and the solvent, easily removed after the growth process, high purity, and low toxicity. In growth from high-temperature solutions the so-called top-seeded solution growth (TSSG) method is widely used. Figure 1.12 shows three examples of single crystals grown by the TSSG method. Note the well-defined crystallographic equilibrium faces. As mentioned above, only a limited part of a solution can be transferred into the solid state depending on the phase diagram. It is shown from Fig. 1.13 that the growth is practicable in the range $\Delta x_{0}=x_{\mathrm{e}}-$ $x_{0}$. The obtainable crystal size $V_{\mathrm{cr}}$ is a function of the steepness of the liquidus curve and the inserted solution charge $V_{\mathrm{ch}}$. The relative crystal yield described

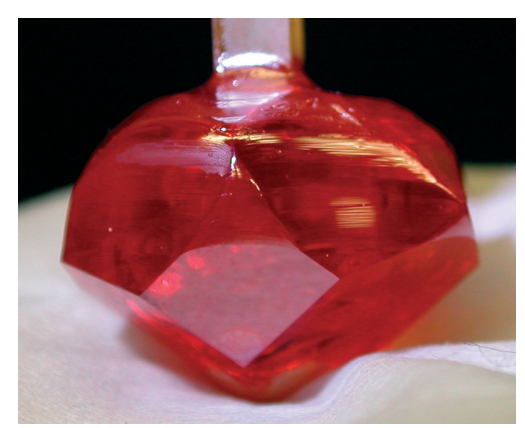

(a)

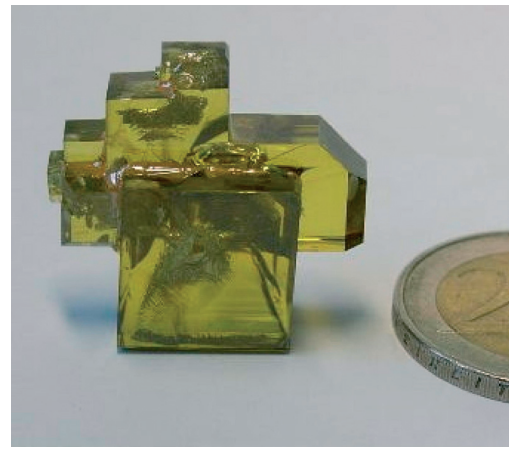

(b)

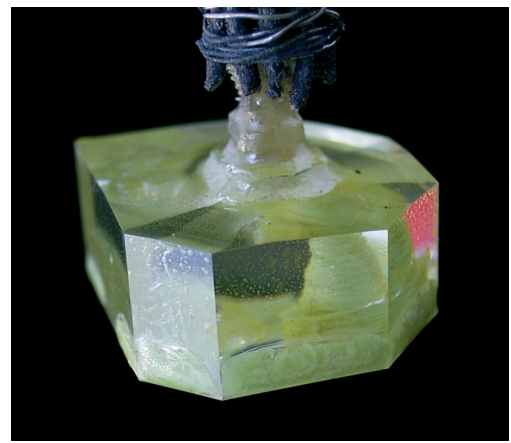

(c)

Fig. 1.12 Three examples for crystal growth from solution: Boron-sillenite $\mathrm{Bi}_{24} \mathrm{~B}_{2} \mathrm{O}_{39}$ (PSG: 23) [15] (top left), $\mathrm{Bi}_{2} \mathrm{ZnB}_{2} \mathrm{O}_{7}$ (PSG: $m m 2$ ) [unpublished], $\mathrm{Bi}_{2} \mathrm{Ga}_{4} \mathrm{O}_{9}$ (PSG: $\mathrm{mmm}$ ) [22] (bottom). 

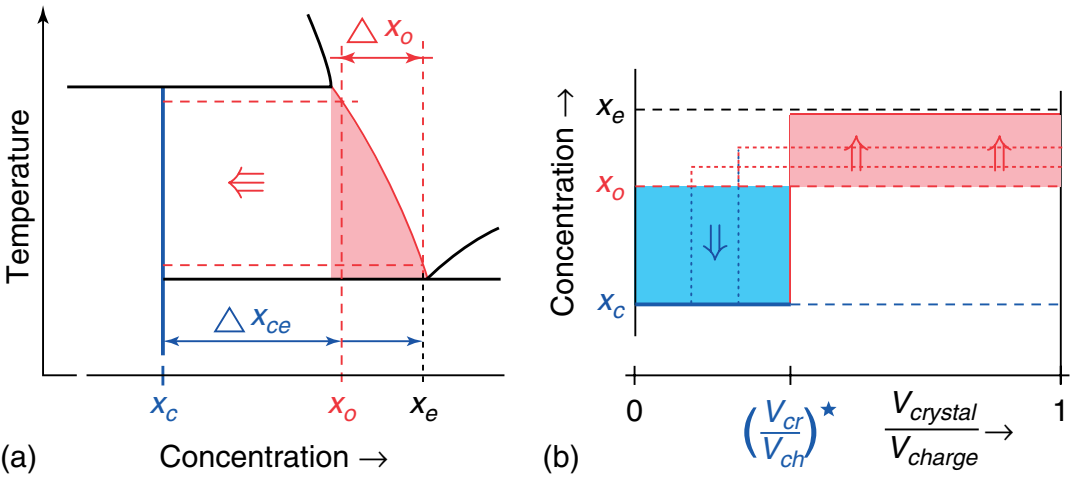

Fig. 1.13 Phase diagram of an incongruently melting compound $x_{c}$ and representation of the limited yield of crystal size at growth from solution.

by the ratio $\left(\frac{V_{\mathrm{cr}}}{V_{\mathrm{ch}}}\right)^{*}$ can be estimated by a balance equation (see right image in Fig. 1.13)

$$
\left(x_{\mathrm{o}}-x_{\mathrm{c}}\right) \cdot\left(\frac{V_{\mathrm{cr}}}{V_{\mathrm{ch}}}\right)^{*}=\left(x_{\mathrm{e}}-x_{\mathrm{o}}\right) \cdot\left[1-\left(\frac{V_{\mathrm{cr}}}{V_{\mathrm{ch}}}\right)^{*}\right]
$$

to be:

$$
\left(\frac{V_{\mathrm{cr}}}{V_{\mathrm{ch}}}\right)^{*} \approx \frac{x_{\mathrm{e}}-x_{\mathrm{o}}}{x_{\mathrm{e}}-x_{\mathrm{c}}}=\frac{\Delta x_{\mathrm{o}}}{x_{\mathrm{e}}-x_{\mathrm{c}}}
$$

An estimation of the relative crystal size is based on the corresponding phase diagrams. Using these equations the yields $\left(\frac{V_{\text {cr }}}{V_{\mathrm{ch}}}\right)^{*}$ represent for $\mathrm{KNbO}_{3} 94 \%$, for $\mathrm{BaTiO}_{3} 18 \%$ and for $\mathrm{Bi}_{2} \mathrm{Al}_{4} \mathrm{O}_{9} 7 \%$ (!). Crystal growth of $\mathrm{ZnSe}$ from a SnSe solution zone by the traveling heater method (THM) is an example of using a suitable solvent [23], see Fig. 1.14. ZnSe is a high-melting semiconducting compound with a melting point at about $1525^{\circ} \mathrm{C}$. Since the application of silica ampoules is limited up to about $1200^{\circ} \mathrm{C}$, the solvent for ZnSe should be an end member of a eutectic system with a eutectic line clearly below $1200{ }^{\circ} \mathrm{C}$. SnSe melts at about $900{ }^{\circ} \mathrm{C}$ and the eutectic line is at about $850{ }^{\circ} \mathrm{C}$. If no detailed data are available then the rule of Kordes [24] may be helpful for proposing an approximate phase diagram. This rule states in a eutectic system that the higher the difference between the melting temperatures of the end members the narrower the eutectic composition is located at the end member with the lowest melting temperature. Figure 1.15 shows a simple eutectic system, and on the right side some examples for the validity of the rule of Kordes if a linear relationship of this rule is fitted. The rule is very well fulfilled by the quasibinary system $\mathrm{ZnSe}-\mathrm{SnSe}$ (see Fig. 1.15, left). Assuming that two components form a eutectic system and the melting points are known than the eutectic composition can be estimated on the basis of the rule of Kordes. Knowing these three points, the approximate path of the liquidus lines can be found. 

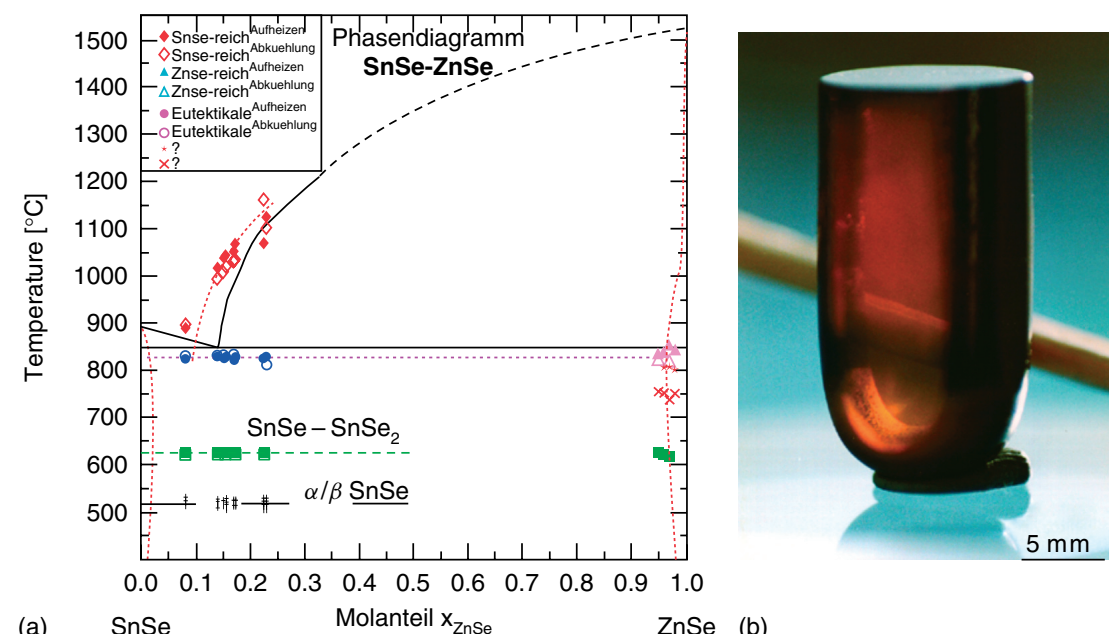

(a)

SnSe

Molanteil $\mathrm{x}_{\mathrm{ZnSe}}$

(b)

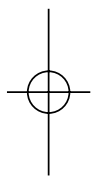

(c)

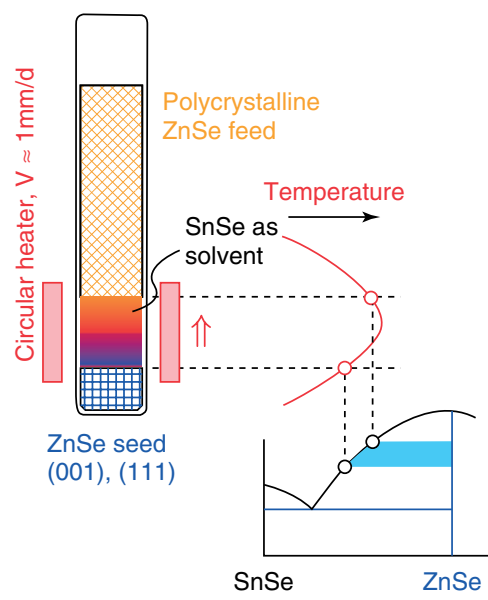

Fig. 1.14 The quasibinary phase diagram $\mathrm{SnSe}-\mathrm{ZnSe}$ and the setup for the traveling heater method (THM). ZnSe single crystal grown by THM and using SnSe as solvent (top right).

\section{3 .4}

\section{Materials with Solid-Solid Phase Transitions}

Solid/solid phase transitions restrict the possibilities of successful crystal growth. Depending on the types of phase transitions additional structural defects will be involved in the grown ingot during the cooling process. A phase transition handicap can be avoided if there exists a liquidus line at lower temperatures than the transition temperature. Such a case is demonstrated in the right image of Fig. 1.8. An example is $\mathrm{BaTiO}_{3}$ showing a congruent melting point at $1618{ }^{\circ} \mathrm{C}$ [25]. At $1460{ }^{\circ} \mathrm{C}$ there is a phase transition from hexagonal to cubic $\mathrm{BaTiO}_{3}$. 


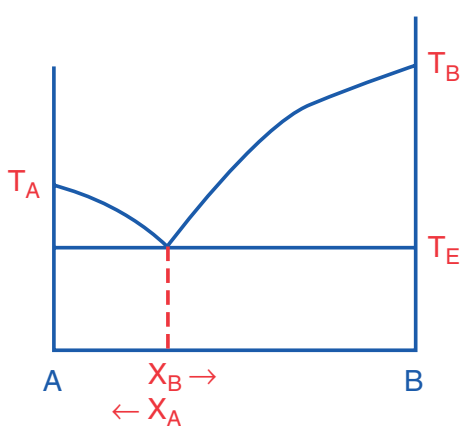

(a)

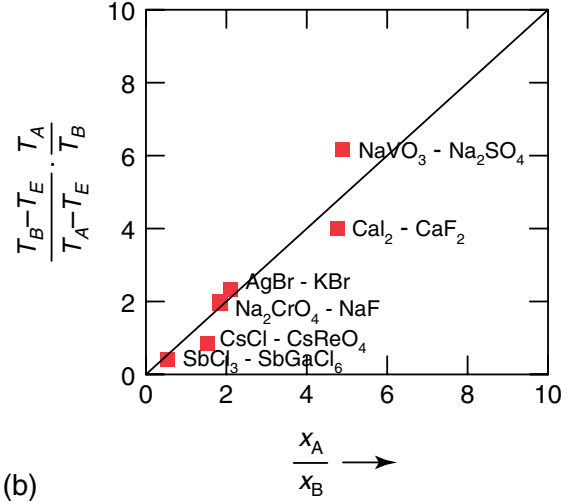

Fig. 1.15 Simple eutectic system and some examples for the validity of the rule of Kordes.

Successful growth is possible by the TSSG method using a mixture containing an excess of $\mathrm{TiO}_{2}$. Furthermore, the cubic phase (PSG: $m 3 m$ ) is transformed into the ferroelectric tetragonal phase (PSG: $4 \mathrm{~mm}$ ) at about $120{ }^{\circ} \mathrm{C}$. Additional phase transitions into a orthorhombic $(\mathrm{mm} 2)$ and rhombohedral $(3 \mathrm{~m})$ phase will take place at $9{ }^{\circ} \mathrm{C}$ and $-90{ }^{\circ} \mathrm{C}$, respectively. Ferroelectric phase transitions are correlated with the formation of domain structures obeying the laws of group theory. Some examples of ferroelectric phase transitions are given in the left image of Fig. 1.16. In many cases the phase transitions "are accepted" by the grown crystal. Single-domain material can be formed by applying a high voltage electric field in such cases like $\mathrm{BaTiO}_{3}, \mathrm{KNbO}_{3}$ and the ferroelectric tungsten bronzes $\mathrm{SBN}$ and CBN. A special situation is given for $\mathrm{LiNbO}_{3}$. Single-domain $\mathrm{LiNbO}_{3}$ is produced by applying an electric field during the growth process because the phase transition $\overline{3} m \rightarrow 3 m$ is several degrees below the melting temperature.

Cracking or distortion occurs if the thermal expansion is strongly influenced by the phase transition. The bottom left image of Fig. 1.16 shows the anomalous thermal expansion in the [001] and [hk0] direction of the tetragonal calcium barium niobate. This material undergoes a ferroelectric phase transition of the type $4 / \mathrm{m} \mathrm{mm} \longrightarrow 4 \mathrm{~mm}$ and formation of $180^{\circ}$ domain structure. Potassium lithium niobate shows the same transition type characterized by cracking along ( $h k 0)$ faces (see Fig. 1.16, right).

1.3 .5

\section{Growth from Aqueous Solution}

The widely used crystal growth from aqueous solutions can be described in the same manner as growth from high-temperature solutions. Figure 1.17 shows a common phase diagram of a system $\mathrm{H}_{2} \mathrm{O}$-anhydrous salt. It must be pointed out that in many cases salt compounds exist with different water content in the crystalline structure. Salts with a water content are regarded as discrete peritectic melting compounds. Based on the phase diagram type of Fig. 1.17 these compounds 


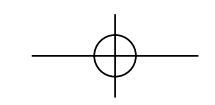

$22 \mid 1$ Phase Diagrams for Crystal Growth

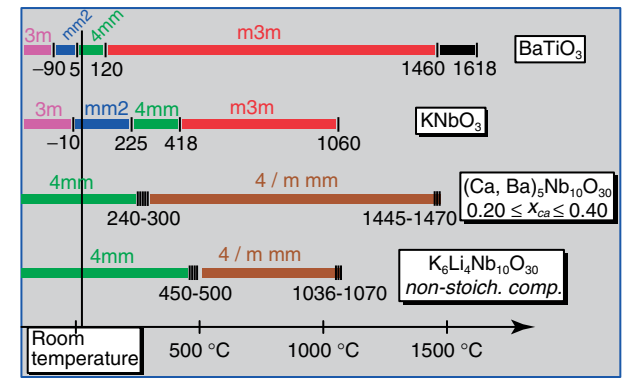

(a)

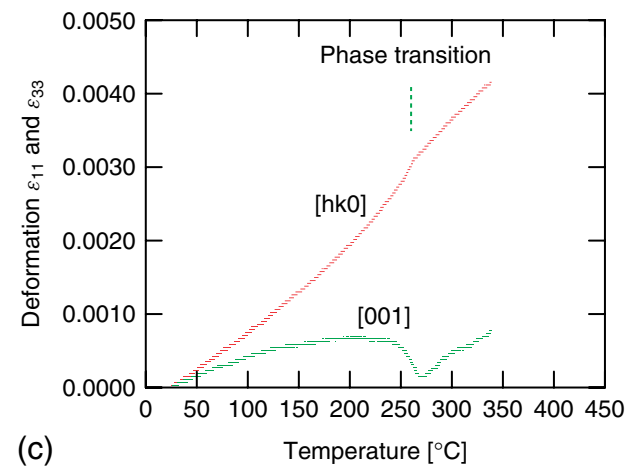

Fig. 1.16 Some ferroelectric compounds and their phase transition types and temperatures. Different thermal expansion of calcium barium niobate in [hk0] and [001] direction. Cracking along ( $h k 0)$ faces in potassium lithium niobate caused by crossing the phase transition temperature at about $460^{\circ} \mathrm{C}$.

can only be grown within a limited temperature region. The higher the growth temperature the lower the water content in the salt. For this reason, only a limited number of compounds can be obtained as anhydrous salt. The right image in Fig. 1.17 shows solubility curves of several salts. It can be seen that in the case of $\mathrm{NaI}$ the access to the anhydrous salt is only possible at a temperature higher than about $65^{\circ} \mathrm{C}$. Convenient growth conditions are given if there is a moderate slope $d T / d x$. Unfortunately, sodium chloride as the most common salt on earth shows a very steep dependence $d T / d x$, and it is difficult to grow large crystals.

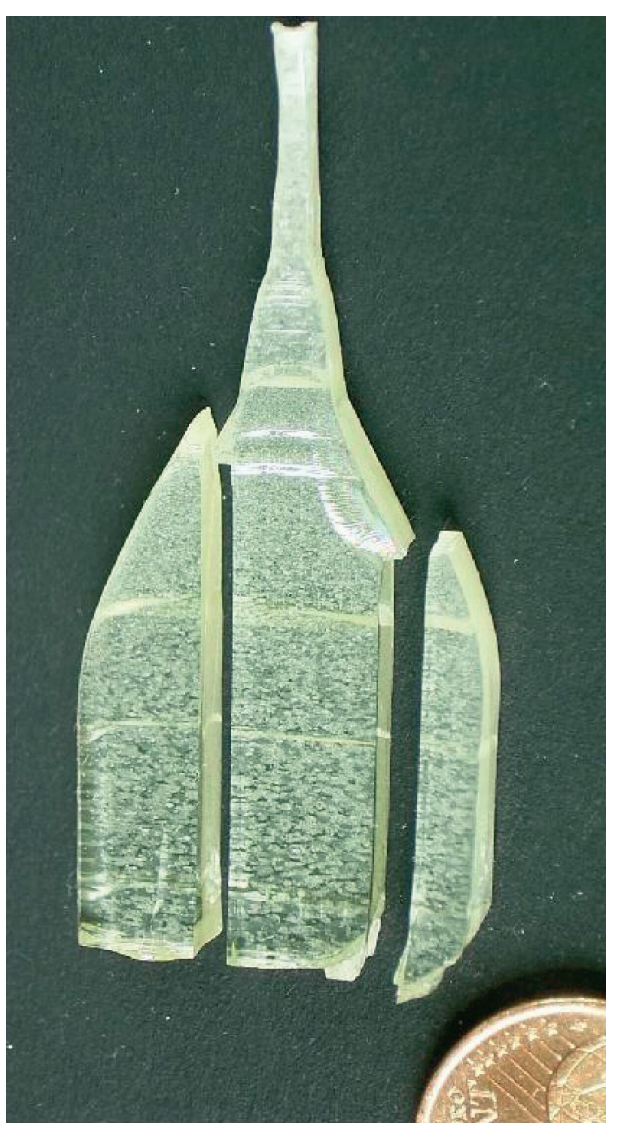

(b) 

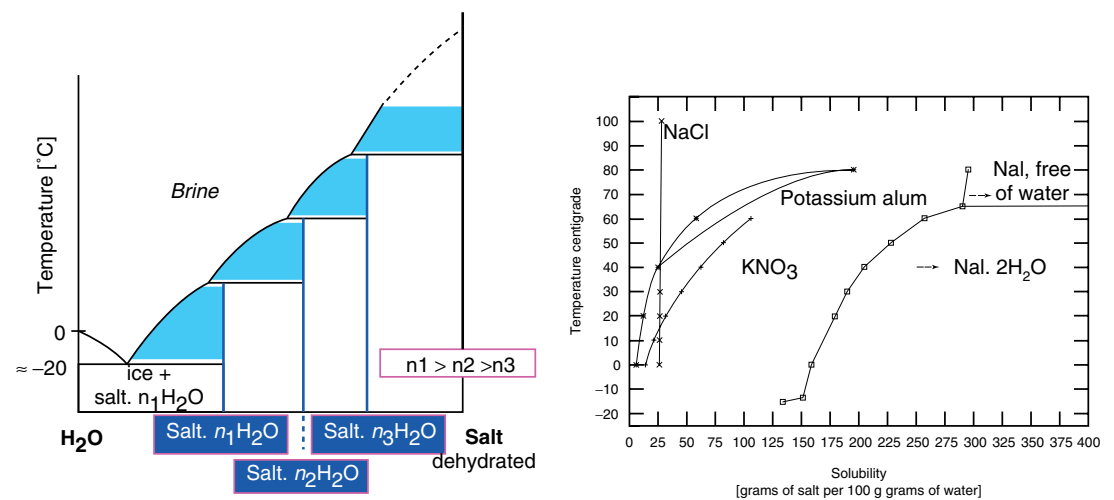

Fig. 1.17 Fictive phase diagram of a system $\mathrm{H}_{2} \mathrm{O}$-salt with several compounds salt $\cdot n \mathrm{H}_{2} \mathrm{O}$ (left). Real solubility curves of some salts (right).

\subsection{6}

\section{No Correlation to Phase Diagrams: Anisotropic Growth}

Phase diagrams have only a thermodynamic background, but actual crystal growth is also influenced by crystallographic characteristics, by kinetics, and by technological parameters of the growth method. Materials with a cubic symmetry show isotropic physical properties. Consequently, cubic crystals take an isometric shape and grow with small differences in unequal [hkl] directions as long as crystals are grown in stable growth conditions. Otherwise, unstable growth may lead to dendrites, to platelet growth by the leading-edge growth mechanism (Scheel and Niedermann [26]), or to needles and whiskers. All noncubic materials are characterized by a more or less pronounced anisotropic growth behavior. In all other crystal systems the habit is intermediate between two singularities referred to as plate and needle shaped (see Fig. 1.18). This means that crystals can be elongated parallel to a symmetry dominated axis, e.g. the $c$-axis in the tetragonal, hexagonal and trigonal system or the $b$-axis in the monoclinic system. On the other side, in the case of plate-shaped growth the influence of the symmetry dominated axis is extremely suppressed.

An additional aspect of anisotropic growth is related to crystals with polar structures. In particular, crystals with the point symmetry groups $2,3,3 \mathrm{~m}, 4,4 \mathrm{~mm}$, 6, $6 \mathrm{~mm}$ can show a ratio in growth velocities along the polar axis up to $10(!)$.

1.4

\section{Conclusions}

Phase diagrams are the complete or partial graphical description of the existence of an element or a compound in the pressure-temperature-composition $\left(p-\mathrm{T}-x_{i}\right)$ space. The validity of nearly equilibrium conditions are assumed. The knowledge 


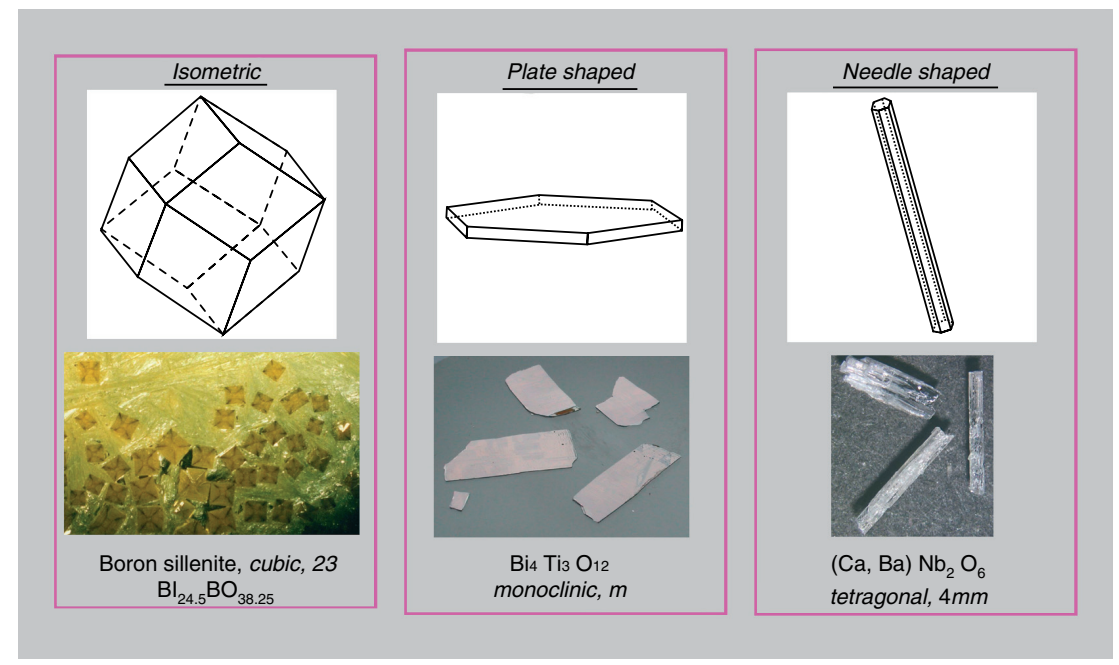

Fig. 1.18 The three basic types of growth behaviors and typical examples.

and understanding of phase diagrams are the most important condition both for the selection of the growth principle and the adjusting of several technological parameters. For this reason there are several phase diagram collections and software programs for calculation of phase relationships.

Many published phase diagrams have errors and/or inaccurate data. The thermal analysis (differential thermal analysis (DTA), differential scanning calorimetry (DSC) and thermogravimetry (TG)) in combination with phase analysis by X-ray diffraction are the main methods for the investigation of phase diagrams in the periphery of a crystal growth lab. Special measurement methods (e.g. Bourdon manometer) are needed for phase analysis if any gaseous state must be considered. Furthermore, the thermomechanical analysis (TMA) is a very sensitive method for detection and characterization of solid/solid phase transitions.

The Gibbs phase rule is the most important tool for checking the correctness of determined phase relations. There are also some additional useful rules like the rule of Kordes for selection of applicable phase diagrams.

In all cases of crystal growth from solution, the precise knowledge of the liquidus curve is necessary because inserting a seed crystal into the solution requires conditions close to the thermal equilibrium. Finally, phase transitions of first, second or higher order can influence successful growth and must be considered in (re)investigations of phase-diagram studies. Note that only a thermodynamic background is reflected by phase diagrams. Actual growth conditions can be markedly influenced by crystallographic characteristics, by kinetics and by technological parameters. More or less anisotropic growth behavior must be expected in materials with lower crystal symmetry. 


\section{Acknowledgements}

The author thanks Dr.-Ing. Hans Scheel for many helpful advices and discussions.

\section{References}

1. C. N. R. Rao and K. J. Rao, 1978, Phase Transitions in Solids, McGraw-Hill Inc.

2. C. G. Bergeron and S. H. Risbud, 1984, Introduction to Phase Equilibria in Ceramics, The American Ceramic Society, Westerville, OH, USA.

3. C. H. P. Lupis, Chemical Thermodynamics of Materials, Elsevier Science Publishing Co., Inc., New York, 1983.

4. Ceramics WebBook - evaluated data, guide to data centers sources, tools resources: www.ceramics.nist.gov/ webbook/glossary/ped/a.htm.

5. Phase Equilibria Diagrams - Phase Diagrams for Ceramics, The American Ceramic Society \& NIST: www.ceramics. org/publications/phasecdform.asp

6. GNUPLOT (www.gnuplot.info): a command-line-driven interactive data and function plotting utility (for PC).

7. O. Kubaschewski and C. B. Alcock, 1979, Metallurgical Thermochemistry, Pergamon Press, Oxford.

8. H. Okamoto and T. B. Massalski, 1991, "Thermodynamically Improbable Phase Diagrams”, J. Phase Equil. 12, 148-167.

9. D. Elwell and H. J. Scheel, 1975, Crystal Growth from High-Temperature Solutions, Academic Press, London, New York.

10. E. M. Levin and C. L. McDaniel, 1962, "The system $\mathrm{Bi}_{2} \mathrm{O}_{3}-\mathrm{B}_{2} \mathrm{O}_{3}$ ", J. Am. Ceram. Soc. 45, 355-360.

11. M. Burianek and M. Muehlberg, 1997, "Crystal growth of boron sillenite $\mathrm{Bi}_{24} \mathrm{~B}_{2} \mathrm{O}_{39}$ ", Cryst. Res. Technol. 32 , 1023-1027.

12. M. Burianek, P. Held, and M. Mueht berg, 2002, "Improved single crystal growth of boron sillenite " $\mathrm{Bi}_{24} \mathrm{~B}_{2} \mathrm{O}_{39}$ " and investigation of the crystal structure", Cryst. Res. Technol. 37, 785-796.

13. H. J. Scheel and R. H. Swendsen, 2001, "Evaluation of experimental parameters for growth of homogeneous solid solutions", J. Cryst. Growth 233, 609-524.
14. H. J. Scheel, 2006, "Theoretical and technological solutions of the striation problem", J. Cryst. Growth 287, 214-223.

15. D. Rytz and H. J. Scheel, 1982, "Crystal Growth of $\mathrm{KTa}_{1-x} \mathrm{Nb}_{x} \mathrm{O}_{3}(0<x \leq$ 0.04) Solid Solutions by a Slow-Cooling Method", J. Cryst. Growth 59, 468-484.

16. P. Capper, (ed.) 1994, Properties of Narrow Gap Cadmium-based Compounds, Institution of Engineering and Technology, London.

17. M. Muehlberg, P. Rudolph, C. Genzel, B. Wermke, and U. Becker, 1990, "Crystalline and chemical quality of CdTe and $\mathrm{Cd}_{1-x} \mathrm{Zn}_{x}$ Te grown by the Bridgman method in low temperature gradients", J. Cryst. Growth 101, 275-280.

18. W. Albers and C. Haas, "Stöchiometrie, part I: Existenzgebiet, part II: Punktfehler und die Regelung ihrer Konzentration, part III: Die Bestimmung von Existenzgebieten", Philips Techn. Rdsch. 1969, 30, 74-81 (part I); 1969/70, 30, 110-116 (part II); 1969/70, 30, 143-148 (part III).

19. M. Mühlberg and D. Hesse, 1983, "TEM Precipitation Studies in Te-rich as-grown PbTe single crystals", phys. stat. sol. (a) 76, 513-524.

20. H. J. Scheel, J. G. Bednorz, and P. Dill, 1976, "Crystal Growth of Strontium Titanate $\mathrm{SrTiO}_{3}$ ", Ferroelectrics 13, 507-509.

21. M. Burianek, S. Haussühl, M. Kugler, V. Wirth, and M. Mühlberg, 2006, "Some physical properties of boron sillenite: $\mathrm{Bi}_{24.5} \mathrm{BO}_{38.25}$ ", Cryst. Res. Technol. 41, 375-378.

22. J. Schreuer, M. Burianek, M. Mühlberg, B. Winkler, D.J. Wilson, and H. Schneider, 2006, "Crystal growth and elastic properties of orthorhombic $\mathrm{Bi}_{2} \mathrm{Ga}_{4} \mathrm{O}_{9} "$, J. Phys.: Condens. Matter 18, 10977-10988. 


\section{1 Phase Diagrams for Crystal Growth}

23. I. Dohnke, M. Mühlberg, and W. Neumann, 1999, "ZnSe single crystal growth with SnSe as solvent”, J. Cryst. Growth 198/199, 287-291.

24. E. Kordes, 1927, "Die eutektische Gefrierpunktserniedrigung in binären Gemischen", Z. anorg. allg. Chemie 167, 97.
25. V. Belruss, J. Kalnajs, and A. Linz, 1971, "Top-seeded solution growth of oxide crystals from nonstoichiometric melts", Mater. Res. Bull. 6, 899-906.

26. H. J. Scheel and Ph. Niedermann, 1989, "Growth Mechanisms of $\mathrm{YBa}_{2} \mathrm{Cu}_{3} \mathrm{O}_{7-x}$ Platelet Crystals from STM/SEM Investigations", J. Cryst. Growth 94, 281-284. 